\title{
LAÇOS (IN)VISÍVEIS NO ESPAÇO ESCOLAR: A TEMÁTICA INDÍGENA E OS PRINCÍPIOS DO BUEN VIVIR
}

(In)visible Ties in the School Space: the Indigenous Theme and Buen Vivir's Principles

\author{
Fabiane da Silva Prestes ${ }^{1}$ \\ Paulo Evaldo Fensterseifer ${ }^{2}$
}

\begin{abstract}
Resumo: $O$ ensino da temática indígena passou a figurar como obrigatório nos estabelecimentos de ensino básico a partir da entrada em vigor da Lei 11.645/2008. Apesar de suas lacunas, a Lei insere-se nos esforços para o reconhecimento e respeito aos coletivos indígenas, promovendo um diálogo intercultural. Em que pese este significativo avanço legislativo, instituir as propostas legais representa um desafio. Este artigo, produzido desde pesquisas sobre história, cultura e ancestralidade indígena, tem como objetivo propor a interlocução da temática indígena no espaço escolar a partir dos princípios que fundamentam o Buen Vivir. Em termos metodológicos, trata-se de uma pesquisa qualitativa, uma vez que se buscam formas de (re)interpretar a questão indígena a partir de saberes outros. Desse modo, a (re)construção do conhecimento sobre a temática indígena no espaço escolar requer um diálogo qualificado entre gerações, capaz de permitir que a aprendizagem promova a autonomia e contribua para uma formação cidadã voltada para o respeito à natureza e a todas as formas de vida. Por fim, compreende-se que a correta inclusão da temática indígena na escola promova o fortalecimento do respeito e o reconhecimento da diversidade cultural, minimizando a dívida da República com esta parte de si.
\end{abstract}

Palavras-chave: Ancestralidade. Buen Vivir. Educação.

Abstract: The teaching of indigenous themes started to appear as mandatory in basic education establishments after the implementation of the law 11.645/2008. Despite its gaps, the law is part of efforts to recognize and respect indigenous groups, promoting intercultural dialogue. In spite of this significant legislative advancement, implementing legal proposals represents a challenge. This article has been produced from research on history, culture and indigenous ancestry aiming to propose the interlocution of the indigenous theme in the school space from the principles that substantiate the Buen Vivir. In methodological terms, it is a qualitative

\footnotetext{
${ }^{1}$ Doutora em Ciências pela Universidade do Vale do Taquari. Mestre em Direito pela Universidade Regional do Noroeste do Estado do Rio Grande do Sul. Especialista em Educação Ambiental pela Universidade Federal de Santa Maria. Bacharel em Direito pela Universidade Regional Integrada do Alto Uruguai e das Missões. Bolsista PNPD em Estágio Pós-doutoral no Programa de Pós-graduação em Educação nas Ciências da Universidade Regional do Noroeste do Estado do Rio Grande do Sul. ORCID: https://orcid.org/0000-0002-7593-8998 E-mail: fabianeprestes@gmail.com

${ }^{2}$ Doutor em Educação pela Universidade Estadual de Campinas. Professor Adjunto do Departamento de Humanidades e Educação e Professor no Programa de Pós-graduação em Educação nas Ciências da Universidade Regional do Noroeste do Estado do Rio Grande do Sul. ORCID: https://orcid.org/0000-0002-4914-5281 E-mail: fenster@unijui.edu.br
} 
research, since it seeks ways to (re) interpret the indigenous question from other cultural sources. Following this perspective, the (re) construction of knowledge about indigenous themes in the school space requires a qualified dialogue between generations capable of allowing learning to promote autonomy and contribute to a citizen formation focused on respect for nature and all forms of life. Finally, it is understood that the correct inclusion of indigenous themes in the school promotes the strengthening of respect and cultural diversity recognition, minimizing the debt of the state concerning this subject.

Keywords: Ancestrality. Buen Vivir. Education.

\section{Introdução}

Temas abordando a questão indígena vêm ganhando espaço no contexto escolar, sobretudo a partir da entrada em vigor da Lei 11.645/08. Apesar, contudo, do significativo avanço legislativo, inserir a temática indígena no âmbito de todo o currículo escolar ainda é um desafio. Nesse contexto, entende-se que os conteúdos relacionados à história e à cultura indígena permanecem interligados com a ancestralidade destes coletivos, a qual é evidenciada a partir do Novo Constitucionalismo da América Latina em seu terceiro ciclo, também reconhecido como plurinacional e comunitário.

Na América Latina é a Constituição da Bolívia, de 2008, que consagra a perspectiva do Buen vivir: modo de vida pautado em saberes tradicionais dos povos que habitavam o continente Abya Yala, que passou a ser denominado América após sua invasão. Destaca-se que Abya Yala, na língua Kuna, significa terra madura, terra viva ou terra em florescimento. Não é possível delimitar, todavia, um significado exato para esta palavra, uma vez que o território era povoado por diferentes grupos originários, os quais possuíam seus costumes, cosmologias e visão de mundo (PORTO-GONÇALVES, 2009).

O Buen Vivir emerge como discurso a partir do final da década de 1990 do século XX, tendo seu ápice nas Assembleias Constituintes dos países do Equador e da Bolívia. Assim, o Buen Vivir é uma perspectiva holística das sociedades indígenas (da América Andina), que decidiram recuperar seus valores e seus códigos de organicidade, os quais foram desprezados desde a colonização do território. Compreendido como filosofia de vida, é sustentado na harmonia das relações entre o indivíduo consigo mesmo, o indivíduo e a sociedade e o indivíduo e o Planeta (todas as formas de vida) (ACOSTA, 2016).

Com a finalidade de ampliar as possibilidades de discussão sobre a questão indígena, este artigo tem como objetivo propor a interlocução da temática indígena no espaço escolar a partir dos princípios que fundamentam o Buen Vivir. Em termos metodológicos, utilizou-se a pesquisa bibliográfica, de natureza exploratória-descritiva por meio do método qualitativo. Foram analisadas legislações, dando-se ênfase à Lei 11.645/2008, entre outros documentos concernentes à inserção da temática indígena no espaço escolar. Dessa forma, é realizado o exame da natureza, do alcance e das interpretações possíveis sobre a temática indígena no espaço escolar, bem como maneiras de (re)interpretá-la a partir de saberes outros. Esse diálogo de saberes pressupõe que a educação se cumpra "não em simples trocas de informações, nem em mero assentimento acrítico a proposições alheias, mas na busca do entendimento compartilhado em todos os que participam da mesma comunidade de vida [...]" (MARQUES, 2002, p. 118). Assim, tomando como aportes teóricos da educação, do neoconstitucionalismo, da descolonização e da temática indígena na escola, tem-se que a questão indígena é um tema negligenciado na tradição educacional republicana e propõem-se a sua (re)construção a partir da interlocução de saberes. 


\title{
2 Para além dos saberes ancestrais em Abya Yala: a transcendência do Buen Vivir
}

O conceito de Abya Yala refere-se a terra em plena maturidade ou terra com sangue vital, apesar de alguns coletivos originários, que habitavam o continente americano anteriormente à grande invasão, atribuírem nomes próprios ao território que ocupavam; "a expressão Abya Yala vem sendo cada vez mais usada por esses povos, objetivando construir um sentimento de unidade e pertencimento" (PORTO-GONÇALVES, 2009, p. 26).

De acordo com Salazar (2015), os sujeitos de Abya Yala continuam vivos e reincorporados à Mãe Terra - Pachamama. Nesse sentido,

\begin{abstract}
El retorno del sujeto de Abya Yala conlleva el reconocimiento y la afirmación del ser y del estar-siendo-en-la Pachamama-con otros. Implica relaciones de intersubjetividad en una comunidad de vida social y de coexistencia armónica indeterminada, en el sentido de que la co-existencia de los sujetos es armónica sin excepcionar el conflicto, por la convivencia misma del sujeto (SALAZAR, 2015, p. 64).
\end{abstract}

A substituição do nome do continente Abya Yala por América e o encobrimento do outro, faz parte do processo de conquista europeu. Nesta perspectiva, Lisboa (2014) considera que, ao batizarem com nomes próprios de sua cultura, os europeus não somente desprezaram as denominações originais dos coletivos que habitavam o continente, mas também inventaram nomes de acordo com projeções deles mesmos, idealizando que este novo mundo fosse uma continuidade da Europa. Eduardo Galeano (2012, p. 150) sintetiza estes primeiros contatos, considerando que, em 1492, "[...] los nativos descubrieron que eran indios, descubrieron que estaban desnudos, descubrieron que existía el pecado, descubrieron que debían obediencia a un rey y a una reina de otro mundo y a un dio de otro cielo".

Essa visão parcial sobre o "descobrimento" da América, portanto, precisa ser desconstruída no espaço escolar e no mundo da vida. "Esta nasce ontologicamente sob o signo do encobrimento, da negação do Outro, da ocultação da miríade de outridades aqui presentes" (LISBOA, 2014, p. 517). Para Todorov (1983, p. 8), na conquista "os índios da América estão ali, bem presentes, mas deles nada se sabe, ainda que, como é de esperar, sejam projetadas sobre os seres recentemente descobertos imagens e ideias relacionadas a outras populações distantes".

Passaram-se quase 500 anos sem que os coletivos indígenas fossem reconhecidos em sua diversidade e sem que seus conhecimentos tradicionais fossem, efetivamente, valorizados como patrimônio cultural destes coletivos. A partir da década de 1980 do século XX é que os movimentos sociais passam a reivindicar por reconhecimento e respeito. São os movimentos sociais que impulsionam as Assembleias Constituintes para que se incorpore nos textos legais, em especial nas Cartas Magnas, o direito à diversidade cultural. Assim, rompe-se com a tradição colonial e faz-se emergir um constitucionalismo transformador (LAURINO; VERAS NETO, 2016).

De tal modo, no primeiro ciclo do Novo Constitucionalismo da América Latina entra em vigor a Constituição da República Federativa do Brasil de 1988, que compreende o constitucionalismo multicultural. No segundo, entram em uso as seguintes Constituições e reformas: Colômbia 1991, Paraguai 1992, Peru 1993, Argentina 1994, Bolívia 1994, Equador 1998, México 1998 e 2001 e Venezuela 1999, as quais compreendem o ciclo do constitucionalismo pluralista. Já no terceiro ciclo entram em vigor as Constituições do Equador 2008 e da Bolívia 2009, as quais representam o constitucionalismo plurinacional (FAJARDO, 2011).

É importante destacar que o Brasil adotou sete constituições, das quais seis entraram em vigor após a Proclamação da República: Constituição de 1891 (Brasil República), Constituição de 1934 (Segunda República), Constituição de 1937 (Estado Novo), Constituição de 1946, 
Constituição de 1967 (Regime Militar) e Constituição de 1988 (Constituição Cidadã). Desse modo, enfatiza-se que a atual Constituição Federal do Brasil rompe não somente com a invisibilidade do indígena, mas também com o caráter tutelar da norma, caracterizando o indígena brasileiro, pela primeira vez em quase cem anos de República, como sujeito de direitos. Essa plenitude de direitos e o reconhecimento da organização social e cultural de cada um dos mais de 300 coletivos indígenas brasileiros (BRASIL, 2012), representa um grande passo para a descolonização.

Essa ruptura com o sistema de poder colonial vem a ser reiterada, de forma mais contundente, pelas novas Constituições do Equador e da Bolívia, uma vez que as referidas cartas reconhecem os saberes tradicionais dos coletivos indígenas. Ademais, a Constituição do Equador positiva o Buen Vivir, de modo que a concepção milenar indígena é traduzida ao mundo jurídico e sociopolítico latino-americano, emergindo numa perspectiva de reconhecimento mundial.

Definir o Buen Vivir é estar consciente de que se trata de um conceito complexo, vivo, não linear, historicamente construído e em constante ressignificação. De acordo com HidalgoCapitan (2012), existem três correntes sobre o Buen Vivir: socialista/estadista, pósdesenvolvimentista/ecologista e indigenista/pachamanista. A primeira aspira construir um biossocialismo republicano, estando vinculada ao pensamento neomarxista moderno. A segunda é caracterizada pela relevância dada à preservação da natureza, estando vinculada ao pensamento construtivista moderno. A terceira relaciona-se à autodeterminação dos povos indígenas, aos elementos espirituais e à cosmovisão andina, estando ligada ao pensamento indígena tradicional, originário e pré-moderno (HIDALGO-CAPITAN, 2012).

O conceito de buen vivir ou vivir bien (oriundo da ancestralidade indígena) não possui uma tradução literal daquilo que se pode entender como "bem viver," posto que cada povo tem sua própria interpretação, a qual é repleta de significados. Mamani (2010), ao recorrer à tradução literal dos termos originais em Aymara e Quéchua, quais sejam Suma Qamaña e Sumak Kawsay, coloca que o primeiro se traduz como Suma - plenitude, sublime, excelente, magnífico, formoso - e Qamaña - viver, conviver, estar e ser. Por outro lado, o segundo traduzse como Sumak - plenitude, sublime, excelente, magnífico, formoso, superior - e Kawsay vida, ser e estar. As conexões, portanto, entre Buen vivir, Suma Qamaña e Sumak Kawsay indicam que a definição que mais se aproxima com a tradição indígena é vida em plenitude, boa vida ou bom viver.

Nesse contexto, trabalhar a temática indígena no espaço escolar a partir dos pressupostos do Buen Vivir, é capaz de alargar os horizontes de discussão, interconectando tal temática com outros temas contemporâneos e que estão inseridos nos calendários de atividades e currículos escolares, uma vez que tal modelo de vida é sustentado por princípios que se complementam e se interconectam, com a finalidade de recuperar os códigos ancestrais de vida. Assim, o Buen Vivir propõe um novo modelo de desenvolvimento baseado em antigas tradições, e seus princípios norteadores representam a conjugação dos pressupostos presentes no novo constitucionalismo, que reafirma o conceito de vida plena almejado pelos coletivos de Abya Yala há milhares de anos, sintetizados nos seguintes princípios: priorizar a vida; fazer acordos em consenso; respeitar as diferenças; viver em complementariedade; ter equilíbrio com a natureza; defender a identidade; aceitar as diferenças; priorizar direitos cósmicos; saber comer; saber beber; saber dançar; saber trabalhar; retomar a Abya Yala; reincorporar a agricultura; saber comunicar-se; ter controle social; trabalhar em reciprocidade; não roubar nem mentir; proteger as sementes; respeitar as mulheres; viver bem e não melhor; recuperar recursos; exercer a soberania; aproveitar a água; escutar os mais velhos (CHOQUEHUANCA, 2010). 
Nessa conjuntura, é possível sintetizar tais princípios em conceitos-chave, a fim de estabelecer interlocuções com outras temáticas que integram o currículo escolar, quais sejam: ancestralidade, cosmovisão, vida como prioridade, complementariedade, reciprocidade, harmonia, equilíbrio, dualidade, tempo cíclico e concepção biocêntrica. Tais conceitos-chave referem-se ao agrupamento de dois ou mais princípios em uma definição similar. Desse modo, é possível reconstruir a forma como a temática indígena vem sendo demonstrada, a qual, na maioria das vezes, restringe-se a atividades lúdicas no mês de abril. Diante da obrigatoriedade de inserção da temática indígena no espaço escolar, faz-se necessário compreender a trajetória de reconhecimento de direitos das pessoas indígenas até se chegar à legislação vigente.

\section{A Lei 11.645/2008 e a superação da invisibilidade histórica no campo jurídico}

Pesquisas arqueológicas demonstram que, no final do primeiro milênio a.C., todo o território brasileiro já era ocupado por povos originários, período em que muitas comunidades dominavam a tecnologia da pedra. A ocupação indígena, portanto, é de, pelo menos, 12 mil anos (FUNARI; PIÑON, 2011). É a partir do "descobrimento", contudo, que os portugueses conferem ao povo (por eles denominado como gentio) a entrada no grande curso da história (CUNHA, 2002).

A invisibilidade indígena, nos mais diversos campos, perdurou por quase 500 anos. Reitera-se que "os povos indígenas foram, dentro da história cuja matriz era o princípio da nacionalidade brasileira, relegados ao esquecimento logo após a chegada dos europeus" (BITTENCOURT, 2013, p. 102).

No campo jurídico, o processo de reconhecimento de direitos transcorreu por três períodos: 1) indiferença total - que tem início com a conquista no século XVI, estendendo-se até o início do século XX - nesse período legislações sequer traziam ressalvas sobre os direitos dos indígenas; 2) caráter tutelar - figuras intermediárias são criadas para representar os grupos indígenas (SPILTN e SPI); nessa época, as discriminações apresentavam-se encobertas pelos signos da proteção; 3 ) reconhecimento de direitos - a partir de 1988, com a entrada em vigor da Constituição Federal, que reconhece o indígena como sujeito de direitos (PRESTES, 2018).

Assim, a partir do final do século XX, ser indígena significa ser portador de um status jurídico que lhe garante reivindicar e exercer direitos. Além disso, assegura-lhe fazer parte de uma coletividade e distinguir-se da sociedade nacional, por identificar-se como indígena ou por perceber-se como descendente de uma população de origem pré-colombiana (CALEFFI, 2003). Cumpre destacar que as Constituições Federais de 1934, 1946 e 1967 ambicionavam incorporar o silvícola à comunhão nacional, e que somente a Constituição Federal de 1988 reconhece o indígena como sujeito de direitos plenos, conferindo-lhe o direito à diferença, à educação escolar indígena e à diversidade cultural, garantindo as práticas próprias de cada sociedade (BRASIL, 1988).

Os movimentos sociais, que se constituíram a partir dos anos 1980 e impulsionaram a promulgação da Carta Magna de 1988, reforçam a luta pelo reconhecimento da diversidade. Tais aspirações refletem um contexto internacional estimulado por mecanismos legais, como a Convenção no 169 sobre Povos Indígenas e Tribais da Organização Internacional do Trabalho (OIT) de 1989, a qual enalteceu os direitos fundamentais dos povos indígenas, reconhecendoos como povos originários, ratificada e promulgada no Brasil por meio dos Decretos $\mathrm{n}^{\circ}$ 143/2002 e n 5.051/2004, e a Declaração da Organização das Nações Unidas (ONU) de 2007 sobre os Direitos dos Povos Indígenas, da qual o Brasil é signatário. 
No final da década de 1980, o movimento indígena passa a reivindicar a efetividade dos dispositivos constitucionais, em especial no que diz respeito ao direito à educação escolar intercultural, autônoma, específica e voltada para o fortalecimento das identidades, culturas e conhecimentos tradicionais, possibilitando, igualmente, o acesso adequado e qualificado aos conhecimentos científicos e técnicos da escola tradicional. Tais reivindicações deram início à reforma da Lei de Diretrizes e Bases da Educação, a fim de que fossem inseridas nesse texto as diretrizes da educação escolar indígena. Nesse contexto, os coletivos indígenas, com o apoio do Conselho Indigenista Missionário - Cimi - e de universidades públicas, reuniram-se para discutir os rumos da educação. Estes encontros de professores indígenas, além de reivindicar a efetividade da educação indígena, promoveram um repensar sobre as políticas públicas da educação para não indígenas (FANELLI, 2018).

Em 1989 é realizado o I Encontro de Educação Escolar Indígena do Mato Grosso. Na oportunidade, indígenas de diversos coletivos reivindicaram, entre outros aspectos relacionados à educação escolar indígena, que "[...] a sociedade envolvente deve ser educada no sentido de abolir a discriminação histórica manifestada constantemente, nas relações com os povos indígenas" (CIMI, 1992, p. 32). Ainda nesta perspectiva, em 1990 é realizado o I Encontro de Professores indígenas de Rondônia, oportunidade em que é elaborado um documento a fim de ser encaminhado ao Senado Federal. Tal documento requer, entre outros pontos, "a colaboração dos senhores senadores para que respeite o índio e suas culturas nas escolas não indígenas e nos livros didáticos" (CIMI, 1992, p. 33). Em 1991, no IV Encontro dos Professores Indígenas do Amazonas e Roraima, é elaborada uma Declaração de Princípios, na qual o $13^{\circ}$ de $15^{\circ}$ princípios declaram: "nas escolas dos não-índios será corretamente tratada e veiculada a história e cultura dos povos indígenas brasileiros, a fim de acabar com preconceitos e racismos" (CIMI, 1992, p. 35). Assim, o protagonismo indígena demonstra preocupação não somente com a efetividade da educação escolar indígena, mas também com a inserção da temática indígena no espaço escolar, como instrumento de superação de preconceitos.

Em 1996 entra em vigor a Lei 9.394, que estabelece as Diretrizes e Bases da Educação Nacional, substituindo a Lei 5.692/71 (instaurada no Regime de Exceção). Acompanhando a perspectiva de participação cidadã e o reconhecimento da diversidade cultural, consagrados pela CF/88, a "nova" LDB prevê que os currículos devem ter uma base nacional comum, e que o "art. $26[\ldots] 4^{\circ} \mathrm{O}$ ensino da História do Brasil levará em conta as contribuições das diferentes culturas e etnias para a formação do povo brasileiro, especialmente das matrizes indígena, africana e europeia" (BRASIL, 1996).

Nesse contexto, em 1997, o Ministério da Educação lança os Parâmetros Curriculares Nacionais, reconhecendo a pluralidade cultural brasileira e a inserindo como tema transversal. $\mathrm{O}$ documento enaltece as "diversas heranças culturais que convivem na população brasileira, oferecendo informações que contribuam para a formação de novas mentalidades, voltadas para a superação de todas as formas de discriminação e exclusão" (BRASIL, 1997, p. 15). Ainda que o texto se mostre ambicioso, ao indicar um processo de superação de discriminação e desigualdades rompe com o paradigma da homogeneidade brasileira, reconhecendo a diversidade cultural e disciplinando que a mesma seja discutida de forma transversal em âmbito escolar.

Efetivamente, o reconhecimento e o respeito à diferença, em âmbito educacional no currículo oficial, emergem a partir da entrada em vigor da Lei 10.639 de 2003, a qual representa uma conquista dos movimentos sociais a favor da causa afrodescendente. Cumpre destacar que tais movimentos, que surgiram na década de 1970 e se intensificaram na de 1980, ambas do século XX, atuaram de forma contundente na Constituinte, conquistando a inclusão de artigos sobre ações afirmativas. Nesse cenário, o então deputado, Paulo Paim, apresenta um projeto de 
lei versando sobre a temática em questão, no entanto o mesmo é arquivado em 1995 (XAVIER; DORNELLES, 2009). Somente em 1999 é aprovado o Projeto de Lei $\mathrm{n}^{\circ} 259$, que estabelece a obrigatoriedade da inclusão da História e da Cultura Afro-Brasileira no currículo oficial da rede de ensino. Tal projeto fora formulado pelos então deputados, Ben-Hur Ferreira e Esther Grossi. Em 2003, a Lei 10.639 é promulgada, promovendo mudanças na LDB, e passa a vigorar com alterações em seus artigos 26-A, 79-A e 79-B.

Nesse sentido, a mudança estrutural proposta por essa legislação abre caminhos para a construção de uma educação antirracista, que acarreta uma ruptura epistemológica e curricular na medida em que torna público e legítimo o "falar" sobre a questão afro-brasileira e africana. Não é, porém, qualquer tipo de fala; é a fala pautada no diálogo intercultural. E não é qualquer diálogo intercultural; é aquele que se propõe ser emancipatório no interior da escola, ou seja, que pressupõe e considera a existência de um "outro", conquanto sujeito ativo e concreto, com quem se fala e de quem se fala (GOMES, 2012, p. 105).

Dessa forma, o currículo estabelece o diálogo intercultural, consagrando a possibilidade de que outras vozes apareçam, rompendo, assim, com o paradigma colonialista. A legislação, contudo, não reconhece a importância da história e da cultura dos coletivos indígenas. Por essa razão, no mesmo ano, a então deputada, Mariângela de Araújo Gama Duarte, apresenta o projeto de Lei 433/03, a fim de suprir a lacuna deixada pela Lei 10.639/03, tornando obrigatória a inclusão da temática indígena no currículo oficial da rede de ensino.

Assim, "por força da Lei, o tema da diversidade começa a sair do plano da transversalidade no currículo, assumindo concretamente o seu lugar no cotidiano escolar" (NASCIMENTO, 2010, p. 234). Cumpre destacar que os Parâmetros Curriculares Nacionais traziam orientações para cada área do conhecimento, além de temas transversais, incluindo a questão indígena no PCN de História e no Tema Transversal da Pluralidade Cultural, todavia, por serem documentos não obrigatórios, serviam apenas como suporte e orientação ao professor.

Com a entrada em vigor da Lei 11.645/08, torna-se obrigatório o estudo da história e da cultura afro-brasileira e indígena em âmbito de todo o currículo escolar, em especial nas áreas de artes e de literatura e história brasileiras (BRASIL, 2008a). Quando a legislação orienta que tais temáticas sejam desenvolvidas, prioritariamente, em determinadas disciplinas, não exclui a importância de que sejam trabalhadas de forma complementar em outras áreas do saber. Cumpre destacar que na Base Nacional Comum Curricular o componente Arte possui caráter de obrigatoriedade nas etapas de Educação Básica (BRASIL, 2018), sendo a música assegurada pela Lei 11.769 de 2008 (BRASIL, 2008b). Dessa forma, as linguagens artísticas, como o teatro, a dança, a música e as artes visuais, podem ser desenvolvidas a partir das dimensões culturais de cada coletivo indígena.

Desse modo, no plano jurídico, a invisibilidade indígena foi superada, no entanto, no plano fático há muitos desafios a ultrapassar a fim de que as propostas da legislação tornem-se efetivas, até porque, como ensina Marques (2000, p. 42), “o mundo da vida factual não é essa pureza idílica". Seria utópico pensar que a "simples" promulgação de uma lei fosse capaz de resgatar anos de exclusão, desrespeito e intolerância.

A fim de efetivar os preceitos legais, em 2015, o Ministério da Educação propôs as Diretrizes Operacionais para a introdução da história e das culturas dos povos indígenas na Educação Básica. Assim, no parecer no 14/2015 da Câmara de Educação Básica do Conselho Nacional de Educação, observou-se que ainda persistem problemas relacionados à representação dos povos indígenas no imaginário social brasileiro, predominando a visão genérica do indígena, representado como um ser do passado, como negação da cultura, uma 


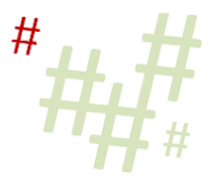

dicotomia entre indígenas vivendo na floresta e em contextos urbanos, características pitorescas e folclóricas.

Nesse sentido, a Câmara de Educação Básica considera que todas as instâncias do sistema nacional de educação devem orientar para a organização e a reorganização de projetos, programas, propostas curriculares e pedagógicas, posto que a "[...] inclusão da temática da história e da cultura dos povos indígenas implica produzir um novo olhar sobre a pluralidade de experiências socioculturais presentes no Brasil" (CÂMARA DE EDUCAÇÃO BÁSICA, 2015 , p. 9). Superar o estereótipo do indígena do passado ou bom selvagem requer, em termos metodológicos, que essa temática seja desenvolvida durante todo o período formativo do estudante, em diferentes disciplinas e com diversas abordagens, sempre atualizadas e plurais.

\section{Laços (in)visíveis na educação: a efetivação da temática indígena a partir dos princípios do Buen Vivir}

Introduzir a temática indígena no espaço escolar, de forma constante, ainda é um desafio para o educador. Não obstante os debates tenham se alargado e a produção acadêmica e bibliográfica sobre o tema tenha ganhado maiores proporções nos últimos anos, pôr em prática requer formação contínua, subsídios e, principalmente, a ruptura de estereótipos. É prudente considerar que "o já existente e o novo se entrelaçam nos significados e conteúdos da tradição cultural, na dimensão do espaço social dos grupos nele integrados e do tempo histórico das gerações que se sucedem" (MARQUES, 1992, p. 559).

É fato inconteste que ocorreram significativos avanços em relação ao reconhecimento e respeito à diversidade, que culminaram na consagração do indígena como sujeito de direitos, contudo, "há uma dificuldade notável em entender as transformações ocorridas nas sociedades indígenas" (WITTMANN, 2015, p. 15). É nesse sentido que a educação deve levar em consideração que a "cultura é uma teia de significados tecida pelo homem" (GEERTZ, 1978), e que todas as coisas que nos cercam e as formas como nos comunicamos fazem parte do "mundo da cultura, ou melhor, das culturas, pois elas se diversificam e se reconstroem de contínuo inseridas num universo de significações" (MARQUES, 2003, p. 15).

O mundo da cultura, no qual os indígenas estão inseridos, deve ser analisado a partir da premissa de que os mesmos possuem um universo cosmológico peculiar, que é perceptível tanto nos princípios que norteiam o Buen Vivir quanto nas particularidades de cada um dos mais de 300 coletivos indígenas brasileiros. É nesse sentido que articular a questão indígena com os referidos princípios reforça a ideia de interlocução de saberes e pressupõe a ruptura com a instrumentalização, dando lugar à interdependência e à complementariedade.

Apesar de a organização curricular ser compartimentada, é necessário estabelecer interconexões entre diferentes áreas, uma vez que, "como a realidade é feita de laços e interações, nosso conhecimento é incapaz de perceber o complexus - o tecido que junta o todo" (MARQUES, 2002, p. 95). De tal modo, sendo a sociedade o conjunto de partes, no qual o todo está no interior destas partes, o pensamento complexo alcança o plano da ética, da solidariedade e da política (MARQUES, 2002).

Promover (re)construção do conhecimento sobre a temática indígena no espaço escolar requer um diálogo qualificado entre gerações, capaz de permitir que a aprendizagem promova a autonomia, contribuindo com a formação cidadã voltada para o respeito à natureza e a todas as formas de vida. Dessa maneira, é urgente que todos assumam o "[...] dever de lutar pelos princípios éticos mais fundamentais como o respeito à vida dos rios e das florestas. Não creio 
na amorosidade entre mulher e homem, entre os seres humanos, se não nos tornarmos capazes de amar o mundo" (FREIRE, 2000, p. 66).

Desse modo, é nítido que a questão ambiental tem importância fundamental. "Ela tem de estar presente em qualquer prática educativa de caráter radical, crítico e libertador" (FREIRE, 2000, p. 67). Nesse contexto, reitera-se que o Buen Vivir deve ser compreendido como um espaço comunitário onde existe reciprocidade, convivência com a natureza e harmonia com a Mãe Terra (HOUTART, 2011). Cumpre ressaltar, ainda, que "as cosmologias ameríndias mobilizam uma multidão de outros mundos e relações, como, por exemplo, os mundos dos animais, das plantas e das divindades" (HEURICH, 2008, p. 79).

Nessa perspectiva de aprendizagem a partir da cultura da vida, daquilo que já se sabe em direção a outros saberes, torna-se possível relacionar os "saberes primeiros [...] da palavra viva" aos "saberes à parte cultivados, os da cultura letrada" (MARQUES, 2002, p. 22, 24), posto que as sociedades indígenas constroem suas narrativas históricas, cosmológicas e educativas a partir da oralidade, e é dessa forma que os saberes são transmitidos de geração em geração. Para além do "encobrimento do outro" (DUSSEL, 1993), desde o processo de conquista, portanto, a escassez de registros escritos é justificada pela tradição oral de como são perpassados os ensinamentos ancestrais. Cumpre destacar que, de acordo com o enfoque dado neste texto, a palavra viva remete aos saberes primeiros, de remota tradição, das civilizações que habitavam o continente americano antes da conquista; saberes estes que não se perderam, apesar de terem sido sufocados.

Continuidades e rupturas fazem parte da história dos saberes. Depois de isoladas e fragmentadas, as ciências defrontam-se com o desafio de reconstruir laços, "[...] através de inter-relacionamentos e de interdependências em novas bases, não de simples sujeição de umas a outras, mas de recomposição de suas especificidades na unidade de suas intercomplementariedades [...]" (MARQUES, 2002, p. 74). Nesse norte, há um vasto movimento em que as ciências se fundem, tornando-se intercomplementares. A partir da necessidade de introduzir a temática indígena no espaço escolar, visualiza-se a ampliação de horizontes em que seja possível interligar ciências, biologia, sociologia, antropologia, história, geografia, filosofia, entre outros. Ou seja, aqueles que despertam interesse pela temática indígena comungam, igualmente, dos interesses de artistas, filósofos, juristas, historiadores e educadores.

Superar a concepção linear de como a temática indígena vem sendo desenvolvida no espaço escolar requer uma "razão dialógica e plural" (MARQUES, 2000, p. 11), na qual a educação deve ser repensada a partir dos dinamismos do mundo contemporâneo, articulando novas questões com velhas tradições. Nesse engendramento, é preciso reconhecer o legado das gerações passadas e, consequentemente, valorizar os saberes ancestrais.

Essa ruptura com a concepção clássica de fragmentação requer o (re)pensar em relação à metáfora da árvore do saber, que vem sendo superada pela ideia de rizoma, uma vez que o conhecimento é dinâmico e passa a ter mais sentido a partir das articulações e interações. "Diferentemente das árvores ou de suas raízes, o rizoma conecta um ponto qualquer com outro ponto qualquer e cada um de seus traços não remete necessariamente a traços da mesma natureza" (DELEUZE; GUATTARI, 1996, p. 13). Esta proposta rizomática é marcada por multiplicidade e coexistências, e contrapõe o pensamento arborescente, sem a intenção de eliminá-lo, mas de intensificar a tensão e a complementariedade.

A relação entre árvore e rizoma, na qual um ultrapassa o outro modificando a sua natureza, torna-se clara na seguinte reflexão: "as sociedades primitivas têm núcleos de dureza, de arborificação, que tanto antecipam o Estado quanto o conjuram. Inversamente, nossas 
sociedades continuam banhando num tecido flexível sem o qual os segmentos duros não vingariam" (DELEUZE; GUATTARI, 1996, p. 90). Assim, ainda que as sociedades originárias possam ser compreendidas a partir do rizoma, há arborescências dentro delas na medida em que as sociedades hodiernas complementam-se a partir do rizoma. No campo da inserção da temática indígena na escola, a radicalidade do pensamento rizomático impulsiona uma guinada necessária, sobretudo quando se fala em incorporar a ancestralidade dos coletivos originários neste diálogo. Urge, pois, uma (re)construção da tematização da questão indígena no espaço escolar.

Reconstruir não significa ignorar o passado que, na cultura de cada homem, continua presente e ativo, vivo e operante, mas impõe que nele se penetrem e atuem novas formas que o transformem e o introduzam na novidade de outro momento histórico e outros lugares sociais (MARQUES, 1992, p. 549).

Inserir temas sobre a questão indígena no universo escolar, portanto, deve ultrapassar o simples cumprimento de um dever legal. Não basta direcionar a temática para o cerne dos currículos; é necessário que tais temas façam sentido, e que seja possível relacionar com o tempo presente e com os dinamismos das sociedades tanto indígenas quanto não indígenas. É preciso reconhecer a contribuição indígena na história e o quanto a cultura brasileira deve à ancestralidade; é fundamental reconhecer que "[...] em todo lugar e a todo momento existe uma verdade talvez adormecida, mas que no entanto está somente à espera do nosso olhar para aparecer [...]" (FOUCAULT, 2014, p. 113).

Nesse contexto, é fundamental que sejam identificados os laços visíveis e aqueles, muitas vezes, invisíveis, mas que sem os quais a sociedade não estaria constituída da forma que está. Heranças da cultura indígena estão presentes em diversos contextos das sociedades não indígenas, como a prática do chimarrão ou mate. Para além da abordagem na história regional, o chimarrão se faz presente nos planos de aula em comemorações alusivas ao Dia do Gaúcho e na Semana Farroupilha no Rio Grande do Sul.

Pois bem, é preciso considerar que este costume foi engendrado pela tradição, posto que se trata de "hábito que identifica a região platina e foi apreendida pelos europeus com o Guarani, que cultivavam a planta da erva-mate, produziam a erva e consumiam o mate num ato de encontro, de fala, de escuta e de troca" (BERGAMASCHI, 2005, p. 104). Sem entrar no mérito sobre a indústria na qual os europeus transformaram tal hábito, é possível identificar que a força da oralidade e da reciprocidade (princípios do Buen vivir) está presente no convite para sorver um chimarrão.

Esta "parte" da história não deve deixar de ser (re)conhecida no espaço escolar, uma vez que o Guarani, "em seu potente silêncio, também guaranizou o europeu e essa marca é profunda que, mesmo renegada ou desconhecida em sua verdadeira autoria, reverbera em indianeidade" (BERGAMASCHI, 2005, p. 104). Nesse contexto, onde a ancestralidade reverbera, é possível entrelaçar disciplinas e conteúdos com saberes e tradições. O mesmo chimarrão que é hábito para não indígenas, para indígenas é sagrado, é lenda e é origem. A roda de chimarrão é um exemplo de fraternidade, complementariedade e reciprocidade. $\mathrm{O}$ seu cultivo é um processo histórico que se complementa com as ciências biológicas e da natureza, uma vez que a Ilex Paraguaiensis é uma planta nativa. Veja-se, pois, que é possível ser inserido em diversos conteúdos curriculares: história, literatura, geografia, ciências, artes, entre outros.

Ainda nesse viés, o modo de vida do Kaingang, "povo do mato", que fez do pinhão uma floresta, merece ser trazido à baila, pois, desde os primeiros contatos, os europeus depararamse com imensas florestas de araucária (Araucaria angustifolia), espécie, atualmente, quase em 
extinção graças ao modelo capitalista de desenvolvimento. O plantio de araucárias pelos Jês foi revelado por arqueólogos na Scientific Reports. O pinheiro de araucária tem grande importância no universo cosmológico deste coletivo indígena, considerado ser vivo, dotado de espírito e fonte viva de saúde; é utilizado em rituais sagrados, como o Kikikói (ritual que garante o bemestar da comunidade em relação às doenças originadas pelo contato com os espíritos dos mortos) (SILVA, 2002). Já seu fruto, o pinhão, é um alimento tradicional, capaz de saciar a fome e evitar as doenças do corpo. Nessa conjuntura, princípios como o da concepção biocêntrica, cultura da vida, harmonia com a natureza e relacionalidade, ficam evidentes, sendo possível serem articulados em outras áreas do saber, como botânica, biologia, geografia, etc.

\section{Considerações finais}

Pelo exposto, percebe-se que os saberes que orientam o modo de ser indígena têm suas raízes na ancestralidade, mais precisamente remontam ao período pré-colombiano. Todo o simbolismo de Abya Yala, além de ser sinônimo de pertencimento, evidencia um período de intensa conexão com a natureza, quando saberes, cosmologias, vidas humanas e não humanas vivenciavam uma relação harmoniosa e de reciprocidade. Tais conexões não foram valorizadas pelos conquistadores, que, além da tentativa de extermínio dos coletivos originários, tentaram encobrir seus costumes e cosmovisões. A tentativa, apesar de enfática, foi frustrada, pois os indígenas não permitiram que suas origens fossem apagadas ou suas heranças esquecidas. Há, portanto, uma reciprocidade (embora na maioria das vezes não pacífica) no processo de colonização, na qual o colonizador também foi "indianizado". Cumpre ressaltar que estas contribuições foram absorvidas no modo de vida não indígena de forma espontânea, sem qualquer violência ou imposição. É preciso reconhecer, portanto, a contribuição indígena para a história e compreender o quanto a sua cultura está presente no modo de vida dos não indígenas.

Nesse contexto, o Buen Vivir emerge como uma possibilidade de (re)conhecimento dos saberes ancestrais, baseado em uma concepção milenar que busca a felicidade para os indígenas e todos os demais grupos humanos. O Buen vivir reforça a importância da profunda comunhão com a terra e com todos os seres vivos de forma complementar. Como proposta metodológica de ensino, os princípios desta teoria/filosofia são capazes de articular diversas áreas do conhecimento de modo intercomplementar.

Procurou-se enfatizar, neste texto, o processo de reconhecimento de direitos dos coletivos indígenas, o qual perpassou um longo período de indiferença, seguido por outro de caráter tutelar, até chegar ao recente reconhecimento de direitos, com a entrada em vigor da Constituição Federal de 1988, que reconhece o indígena como sujeito de direitos. Esta revisão histórica é fundamental para reiterar que o ensino da temática da história e da cultura indígena deve ser desenvolvido por meio de conteúdos, saberes e atitudes, que permitam que o aluno compreenda a mudança de paradigma promovida pela Constituição Federal, a qual reconhece o Brasil como um país pluriétnico. $\mathrm{O}$ (re)conhecimento e o respeito à diversidade na escola, contribuem efetivamente para a tolerância e o diálogo intercultural.

Os movimentos sociais, que se articularam para participar da Assembleia Constituinte e impulsionaram a promulgação da Constituição vigente, seguiram mobilizados a fim de que os direitos constitucionais assegurados se tornassem efetivos. Nesse cenário, novos rumos para a educação começam a ser traçados e a questão indígena ganha espaço no campo da educação, inicialmente pela necessidade de regulamentar a educação escolar indígena e, posteriormente, pela inserção da temática indígena no espaço escolar. Com o reconhecimento da importância da pluralidade cultural e sua inclusão nos Parâmetros Curriculares Nacionais, a temática 
indígena passa a ser desenvolvida de forma transversal, tornando-se contínua após o transcurso de uma década.

Desde 2008, portanto, o ensino da história e da cultura indígenas é obrigatório no âmbito de todo o currículo escolar, em especial nas áreas de artes, literatura e história brasileira. No plano jurídico, a invisibilidade indígena foi superada, contudo, na prática, a temática indígena segue sendo desenvolvida de forma eventual, restrita a atividades comemorativas ao Dia do Índio e transmitida a partir de um estreitamento de visões parciais. Diante disso, o Ministério da Educação identificou as incompreensões em relação às determinações da lei e identificou que persistem abordagens preconceituosas e a reprodução de desinformação.

Assim sendo, este artigo buscou refletir sobre os laços visíveis e invisíveis da questão indígena no espaço escolar, a partir de uma proposta de interlocução e complementariedade com os princípios do Buen Vivir. Tal proposta objetiva romper com a visão eurocêntrica e com a fragmentação do saber, promovendo uma (re)construção da forma como a temática indígena é desenvolvida. Desde os princípios ancestrais indígenas, as vozes desses coletivos podem ser ouvidas, tornando-se possível reconhecer o quanto eles estão presentes no modo de vida dos não indígenas bem como interconectá-los com as diversas áreas do conhecimento.

Cumpre destacar que não se trata de propor soluções definitivas para uma questão tão complexa, uma vez que "mais do que resultados, importa o trabalho da reflexão" (CASTORIADIS, 2007, p. 12). Tem-se, portanto, que é fundamental refletir sobre alternativas contínuas de inserção da temática indígena na escola a partir das concepções dos indígenas, seja por meio de seus textos, suas falas na escola ou da visita em suas terras, promovendo o reconhecimento e a valorização da identidade, da história e da cultura destes coletivos. Por fim, é oportuno reafirmar que a correta inclusão da temática indígena na escola é capaz de promover significativas repercussões, não somente para alunos e professores, mas para o fortalecimento do respeito e do reconhecimento da diversidade cultural que caracteriza a sociedade atual. É, se não saldar, ao menos amenizar a dívida da República com esta parte de si.

\section{Referências}

ACOSTA, Alberto. O bem viver: uma oportunidade para imaginar outros mundos. Tradução Tadeu Breda. São Paulo: Autonomia Literária Elefante, 2016.

BERGAMASCHI, Maria Aparecida. NHEMBO'E: enquanto o encanto permanece! Processos e práticas de escolarização nas Aldeias Guarani. 2005. 273 f. Tese (Doutorado) Universidade Federal do Rio Grande do Sul, Programa de Pós-Graduação em Educação, 2005.

BITTENCOURT, Circe Maria Fernandes. História das populações indígenas na escola: memórias e esquecimentos. In: PEREIRA, Amilcar Araujo; MONTEIRO, Ana Maria (org.). Ensino de histórias afro-brasileiras e indígenas. Rio de Janeiro: Pallas, 2013. p. 101-132.

BRASIL. Constituição da República Federativa do Brasil. Brasília: Senado Federal, 1988.

BRASIL. Parâmetros Curriculares Nacionais para o Ensino Fundamental. Brasília, MEC/SEF, 1997.

BRASIL. Lei n. 9.394, de 20 de dezembro 1996. Estabelece as diretrizes e bases da educação nacional. Diário Oficial [da] República Federativa do Brasil, Brasília, DF, 20 dez. 1996. 
Disponível em: http://www.planalto.gov.br/ccivil_03/LEIS/19394.htm. Acesso em: 10 jun. 2020.

BRASIL. Lei n. 11.645, de 10 de março de 2008. Altera a Lei n. 9.394, de 20 de dezembro de 1996, modificada pela Lei n. 10.639, de 9 de janeiro de 2003, que estabelece as diretrizes e bases da educação nacional para incluir no currículo oficial da rede de ensino a obrigatoriedade da temática "História e Cultura Afro-Brasileira e Indígena". Diário Oficial da União, Brasília, DF, 11 mar. 2008. 2008a. Disponível em http://www.planalto.gov.br/ccivil_03/_Ato2007-2010/2008/Lei/L11645.htm. Acesso em: 10 jun. 2020.

BRASIL. Lei n. 11.769, de 18 de agosto de 2008. Altera a Lei ${ }^{\circ}$ 9.394, de 20 de dezembro de 1996, Lei de Diretrizes e Bases da Educação, para dispor sobre a obrigatoriedade do ensino da música na educação básica. 2008b. Diário Oficial da União: seção 1, Brasília, DF, 19 ago. 2008. Disponível em: https://www2.camara.leg.br/legin/fed/lei/2008/lei-11769-18-agosto2008-579455-publicacaooriginal-102349-pl.html. Acesso em: 4 out. 2020.

BRASIL. Instituto Brasileiro de Geografia e Estatística - IBGE. Censo Demográfico 2010: características gerais dos indígenas. Rio de Janeiro, RJ, 2012. Disponível em:

ftp://ftp.ibge.gov.br/Censos/Censo_Demografico_2010/Caracteristicas_Gerais_dos_Indigenas /pdf/Publicacao_completa.pdf. Acesso em: 15 jan. 2020.

BRASIL. Base Nacional Comum Curricular. Brasília, DF: MEC, 2018.

CALEFFI, Paula. O que é ser índio hoje? A questão indígena na América Latina/Brasil no início do século XXI. In: SIDEKUM, Antônio (org.). Alteridade e multiculturalismo. Ijuí: Editora Unijuí, 2003. p. 175-206.

CÂMARA DE EDUCAÇÃO BÁSICA. Parecer CEB/CNE $\mathbf{n}^{0}$ 15. Relatório do processo 23001.000071/2011-69. Brasília: Ministério da Educação, 2015.

CASTORIADIS, Cornelius. A instituição imaginária da sociedade. 6. ed. São Paulo: Paz e Terra, 2007.

CHOQUEHUANCA, David. Hemos decidido volver a nuestro camino, recuperar nuestros valores y nuestros códigos. In: MINISTERIO DE RELACIONES EXTERIORES. Vivir Bien. La Paz: Ministerio de Relaciones Exteriores, 2010. p. 49-62.

CIMI. Conselho Indigenista Missionário. Com as próprias mãos: professores indígenas construindo a autonomia de suas escolas. Setor de documentação. Brasília: Cimi, 1992.

CUNHA, Manuela Carneiro da. Introdução a uma história indígena. In: CUNHA, Manuela Carneiro da. História dos índios no Brasil (org.). São Paulo: Companhia das Letras, 2002.

DELEUZE, Gilles; GUATTARI, Félix. Mil platôs. Capitalismo e esquizofrenia. Rio de Janeiro: Editora 34, 1996. Vol. 1.

DUSSEL, Enrique. O encobrimento do outro. A origem do mito da modernidade. Petrópolis: Vozes, 1993. 
FAJARDO, Raquel. El Horizonte del Constitucionalismo Pluralista: del multiculturalismo a la descolonización. In: GRAVITO, César R. (coord.). El derecho en América Latina: Un mapa para el pensamiento jurídico del siglo XXI. Buenos Aires: Siglo Veintiuno Editores, 2011. p. 139-159.

FANELLI, Giovana de Cássia Ramos. A Lei 11.645/08: história, movimentos sociais e mudança curricular. 2018. 144 f. Dissertação (Mestrado em Educação: História, Política, Sociedade) - Pontifícia Universidade Católica de São Paulo, Programa de Estudos PósGraduados em Educação: História, Política, Sociedade, São Paulo, 2018.

FOUCAULT, Michel. Microfísica do poder. 28. ed. São Paulo: Paz e Terra, 2014.

FREIRE, Paulo. Pedagogia da indignação: cartas pedagógicas e outros escritos. São Paulo: Editora Unesp, 2000.

FUNARI, Pedro Paulo A.; PIÑON, Ana. A temática indígena na escola: subsídios para os professores. São Paulo: Editora Contexto, 2011.

GALEANO, Eduardo. Los hijos de los días. Buenos Aires: Siglo Veintiuno, 2012.

GEERTZ, Clifford. A interpretação das culturas. Rio de Janeiro: Zahar, 1978.

GOMES, Nilma Lino. Relações étnico-raciais, educação e descolonização dos currículos.

Currículo sem Fronteiras, v. 12, n. 1, p. 98-109, jan./abr. 2012.

HEURICH, Guilherme Orlandi. O primado da relação: aliança, diferença e movimento nas perspectivas indígenas. In: PORTO ALEGRE. Secretaria Municipal de Direitos Humanos e Segurança Urbana. Povos indígenas na bacia hidrográfica do Lago Guaíba. Núcleo de Políticas Públicas para os Povos Indígenas. Coordenação de Direitos Humanos. Porto Alegre: Prefeitura de Porto Alegre, 2008.

HIDALGO-CAPITAN, Luis Antonio. "El Buen Vivir - la (re)creación del pensamiento del PYDLOS”. Cuenca, Ecuador: Universidad de Cuenca, 2012.

HOUTART, François. El concepto de sumak kawsai (buen vivir) y su correspondencia con el bien común de la humanidad. América Latina en Movimiento, Quito, 2011. Disponível em: http://www.alainet.org/es/active/47004. Acesso em: 25 jun. 2020.

LAURINO, Marcia Sequeira; VERAS NETO, Francisco Quintanilha Veras. O novo constitucionalismo latino-americano: processo de (re) descolonização? Juris-Revista da Faculdade de Direito, v. 25, p. 129-140, 2016.

LISBOA, Arnaldo de Melo. De América à Abya Yala - a semiótica da descolonização. Revista Educação Pública, Cuiabá, v. 23, n. 53/2, p. 501-531, maio/ago. 2014.

MAMANI, Fernando Huanacuni. Buen Vivir/Vivir Bien. Filosofía, políticas, estrategias y experiencias regionales andinas. La Paz: Caoi, 2010. 
MARQUES, Mario Osorio. Os paradigmas da educação. Revista Brasileira de Estudos em Pedagogia Bras., v. 73, n. 175, p. 523-546, set./dez. 1992.

MARQUES, Mario Osorio. A aprendizagem na mediação social do aprendido e da docência. 2. ed. Ijuí: Editora Unijuí, 2000.

MARQUES, Mario Osorio. Educação nas ciências: interlocução e complementariedade. Ijuí: Editora Unijuí, 2002.

MARQUES, Mario Osorio. Botar a boca no mundo: cidadania, política e ética. Ijuí: Editora Unijuí, 2003.

NASCIMENTO, Rita Gomes do. Educação escolar brasileira e diversidade étnica e cultural: contribuições dos movimentos negro e indígena para o debate. In: RONCA, Antônio Carlos Caruso; RAMOS, Mozart Neves. Da Conae ao PNE 2011-2020: contribuições do Conselho Nacional de Educação. São Paulo: Moderna, 2010. p. 223-252.

PORTO-GONÇALVES, Carlos Walter. Entre América e Abya Yala - tensões de territorialidades. Desenvolvimento e Meio Ambiente, n. 20, p. 25-30, jul./dez. 2009.

PRESTES, Fabiane da Silva. O bem viver Kaingang: as conexões entre os princípios da teoria do Buen vivir e os saberes tradicionais que orientam o seu modo de ser. 2018. $279 \mathrm{f}$. Tese (Doutorado em Ambiente e Desenvolvimento) - Universidade do Vale do Taquari, Programa de Pós-Graduação em Ambiente e Desenvolvimento, Lajeado, 2018.

SALAZAR, Rodrigo Dias. La Hermenéutica como método para comprender la colonialidad del sujeto de Abya Yala. Sophia, n. 19, p. 47-69, 2015.

SILVA, Sérgio Baptista. Dualismo e cosmologia Kaingang: o Xamã e o domínio da floresta. Horizontes Antropológicos, v. 8, n. 18, p. 189-209, 2002.

TODOROV, Tzvetan. A conquista da América. A questão do outro. São Paulo: Martins Fontes, 1983.

WITTMANN, Luisa Trombini (org.). Ensino (D)e história indígena. Belo Horizonte: Autêntica, 2015.

XAVIER, Maria do Carmo; DORNELlES, Ana Paula Lacerda. "O debate parlamentar na tramitação da Lei 10.639/2003: interrogando o papel da escola na construção da identidade cultural e étnica do Brasil”. EccoS. Revista Científica, São Paulo, v. 11, n. 2, p. 569-586, jul./dez. 2009.

Recebido em agosto de 2020.

Aprovado em novembro de 2020. 